\title{
Aplicación de la fotogrametría terrestre al levantamiento de alzados de edificios singulares
}

José Luis Lerma, Miriam Cabrelles, Ana Elena Seguí, Santiago Navarro, Grupo de Investigación en Fotogrametria y Láser Escáner (GIFLE), Universidad Politécnica de Valencia

\section{INTRODUCCIÓN}

El patrimonio cultural tangible e intangible nos proporciona y transfiere conocimiento singular de diferentes periodos de la historia. El patrimonio tangible siempre está en riesgo de deterioro, destrucción y/o pérdida debido a múltiples causas, que pueden tener su origen tanto en fenómenos naturales (desastres, clima...), como en actuaciones humanas (intervenciones desafortunadas, actos vandálicos, contaminación, uso inadecuado y guerras...). De ahi la necesidad de contar con archivos digitales, registros y documentos científicos que permitan estudiar y preservar la información de los valores patrimoniales (TAKASE, 2006: 407).

La documentación fotográfica se viene utilizando en trabajos de conservación, restauración y difusión del patrimonio cultural desde hace muchos años (incluso siglos). Las imágenes fotográ- ficas registran el estado de conservación de los monumentos en cuestión en el momento en que se realiza la toma (figura 1). Inicialmente las tomas se hacian en formato analógico; en la actualidad, se apuesta claramente por la fotografia digital, si bien coexisten ambos soportes, y toda información existente puede aprovecharse en aras de reproducir métricamente la información contenida mediante procedimientos fotogramétricos a partir de una imagen, pares estereoscópicos o preferiblemente múltiples imágenes (LERMA, 2010: 83-93). Además, desde principios del siglo XXI, el procedimiento fotogramétrico se enriquece mediante el uso de los escáneres láser, sobre todo en tareas de documentación de monumentos, sitios u objetos complejos, independientemente de su dimensión.

La fotogrametría arquitectónica de objeto cercano a partir de imagen y de láser escáner es la herramienta de medición indirecta más

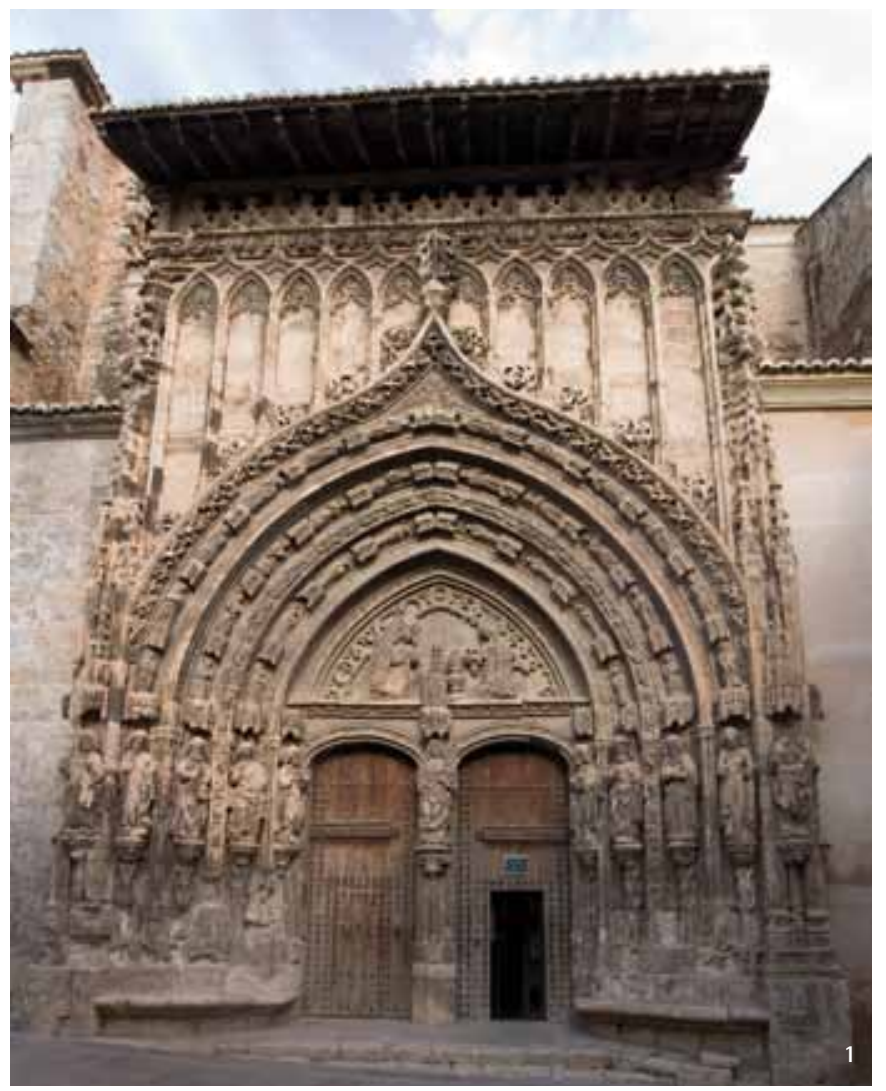

1. Portada de la Iglesia de Santa María, Requena (Valencia). Foto: GIFLE

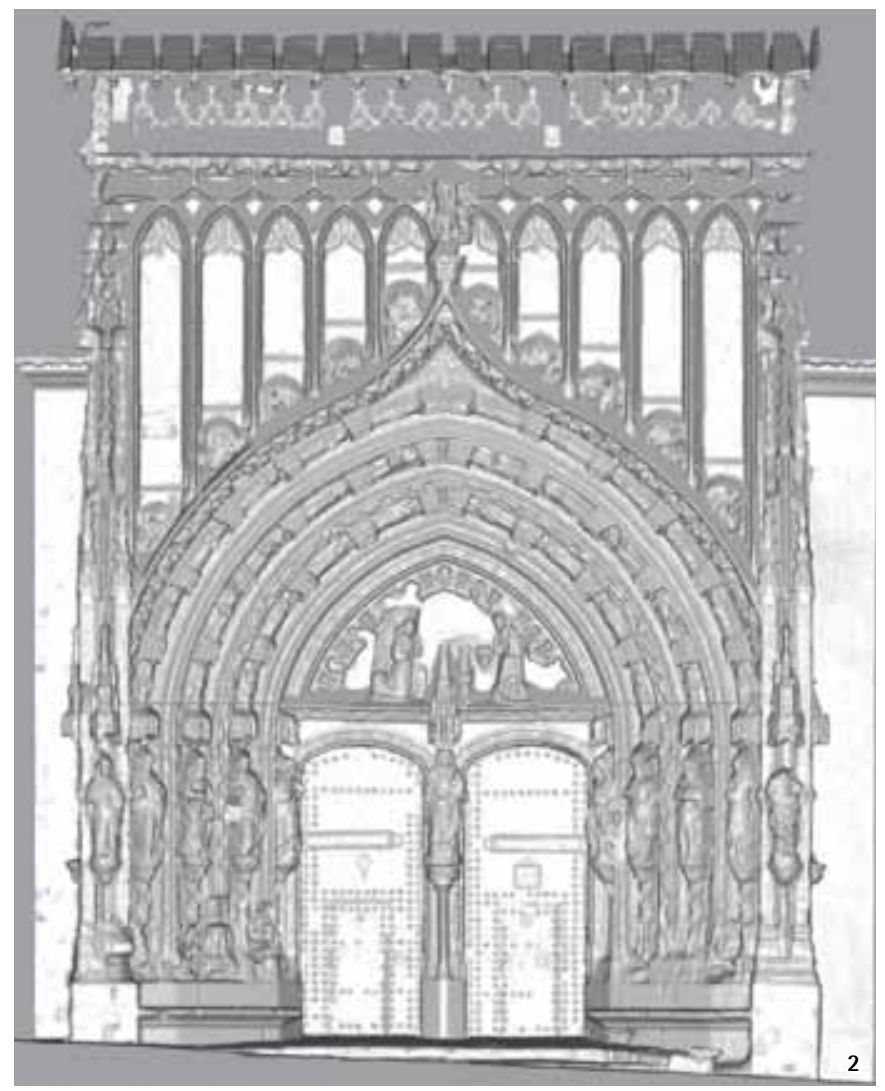

2. Vista ortogonal de la portada. Foto: GIFLE 
extendida en las labores de cartografiado y de documentación patrimonial. Básicamente porque permite realizar el mapeado preciso de volumetrias y superficies a altas resoluciones. Podemos clasificar los productos derivados del levantamiento fotogramétrico en tres niveles (pasando de lo tradicional a lo más avanzado):

- Productos clásicos: planos a diversas escalas de planta y alzados; secciones horizontales y verticales; planos topográficos con curvas de nivel.

- Primeros productos digitales: rectificaciones de objetos planos y ortofotos (ortoimágenes) de superficies no planas, tanto a nivel de planta como de alzado. Las imágenes rectificadas $u$ ortorrectificadas servian de base de las representaciones vectoriales obtenidas en el primer nivel, proporcionando información adicional de textura y color.

- Productos actuales: nubes de puntos en 3D (a color o con niveles de intensidad), modelos digitales sin texturizar (y asignación de color o textura virtual-figura 2-) y modelos fotorrealísticos 3D fieles (asignando la textura verdadera proveniente de las imágenes fotográficas).

Las soluciones fotogramétricas generalmente requieren de otras soluciones topográficas que establezcan inequivocamente el mar-
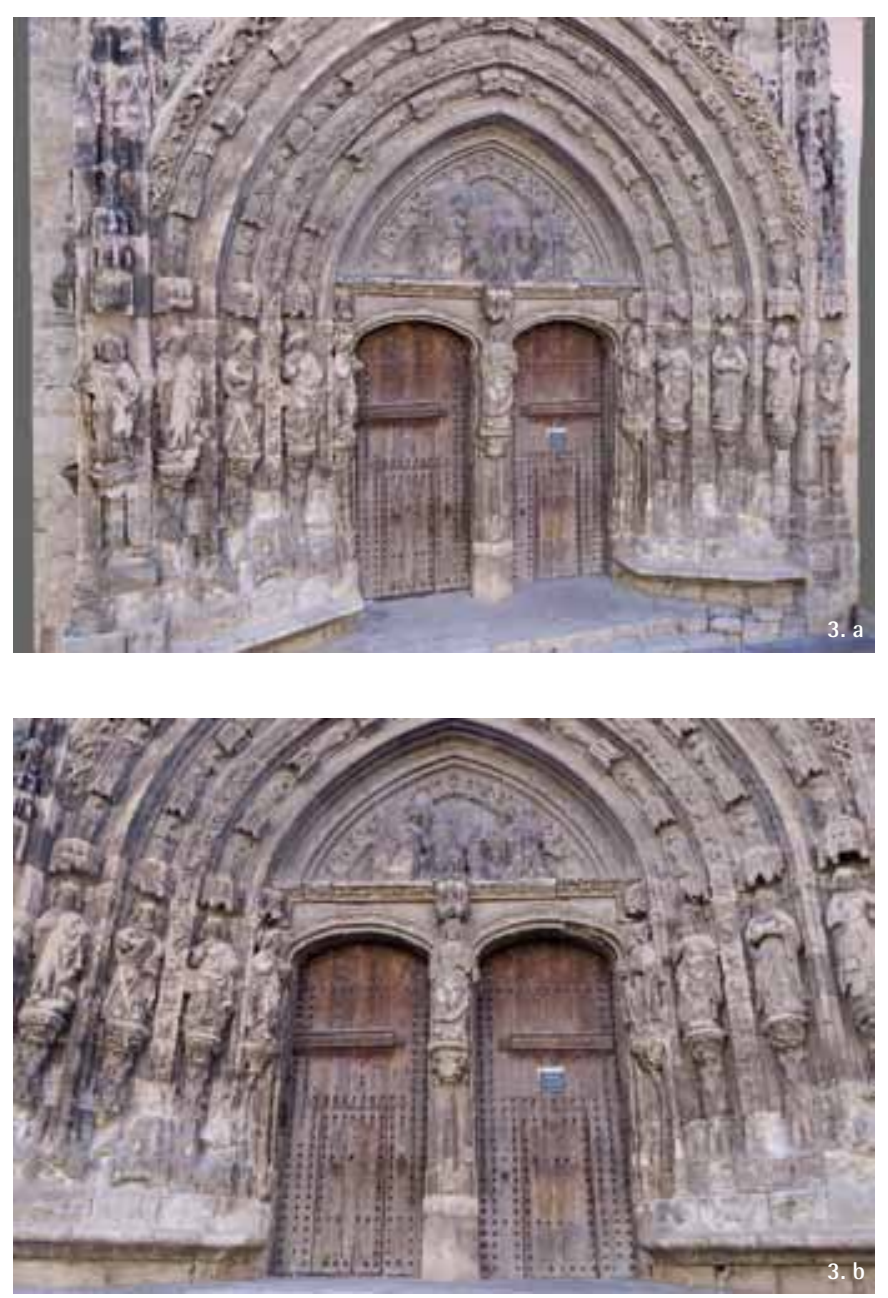

3. Vistas del modelo fotorrealístico 3D: a) vista lateral: b) vista inferior. Fotos: GIFLE co de referencia cartográfico, bien a partir de estación total o mediante sistemas de navegación espacial por satélite (GNSS). Böhler (2006: 89-99) repasa las distintas técnicas 3D de medición directa e indirecta y su adecuación de uso en función de la complejidad del objeto, monumento o sitio y su tamaño.

La demanda de modelos 3D es cada vez mayor en el ámbito de la documentación del patrimonio cultural debido a que permiten el análisis de formas y dimensiones, y la reconstrucción y monitorización de escenarios u objetos complejos a través del tiempo. El campo de la documentación arquitectónica no es una excepción. Los primeros modelos fotorrealísticos $3 \mathrm{D}$ requerian la conjunción de diversas técnicas (topografía, fotogrametria, realidad virtual e Internet) para visualizar escenarios arquitectónicos con máximo grado de similitud. Las resoluciones de las imágenes proyectadas sobre los modelos tampoco eran muy altas. Los modelos fotorrealísticos 3D permitian junto con soluciones fotogramétricas originales previsualizar los eventuales trabajos de restauración. Tal es el caso de la reconstrucción 3D de las pinturas renacentistas ocluidas detrás de la bóveda barroca del altar mayor de la Catedral de Valencia (LERMA; PÉREZ, 2006: 485-491).

A dia de hoy, es mucho más fácil obtener modelos digitales de superficie densos que hace una década, si bien entonces ya existian las soluciones basadas en estación total o GPS. Una solución mejorada son los modelos fotorrealisticos 3D de calidad que pueden obtenerse utilizando procedimientos basados en imágenes (SCHOUTEDEN; POLLEFEYS; VERGAUWEN et ál., 2001: 301-305; CABRELLES; SEGUIi; NAVARRO et ál., 2010). Otra alternativa se basa en integrar datos provenientes del escáner láser y las imágenes capturadas con una cámara externa de alta resolución; generalmente las cámaras digitales que integran los equipos láser no dan suficiente calidad en los modelos que se derivan. Se consigue obtener modelos fotorrealísticos de calidad combinando ambos conjuntos de datos mediante un ajuste en bloque y lanzando procesos de texturización multi-imagen (figura 3) (BIOSCA; NAVARRO; LERMA, 2007; LERMA; NAVARRO; CABRELLES et ál., 2010: 499-507; NAVARRO; SEGUí; PORTALÉS et ál., 2009: 58-63). En otro orden de ideas, la combinación de los dos últimos niveles anteriores facilita la obtención tanto de productos multimedia, videos y animaciones 3D, como de aplicaciones de realidad aumentada.

Este artículo presenta un caso de estudio en el que se integra la solución fotogramétrica basada en escáner láser terrestre y múltiples imágenes para realizar el levantamiento del pórtico gótico en la Iglesia de Santa María, Requena (Valencia). Esta actuación se desarrolló previamente a los trabajos de conservación.

\section{LEVANTAMIENTO DE LA PORTADA GÓTICA DE LA IGLESIA DE SANTA MARÍA DE REQUENA}

El templo, declarado Monumento Histórico Artístico en 1931, es de estilo gótico inicial con intervenciones barrocas del siglo 
XVIII. Su portada data de 1470 y actualmente sufre un alto nivel de deterioro de la piedra. Tiene dos accesos con arco carpanel divididos por un parteluz, que representa a la Virgen con el Niño. En el tímpano, la imagen de la Anunciación. En los lados, entre las arquivoltas y bajo doseletes, se alojan esculturas sobre pedestal de los doce apóstoles. En las arquivoltas se representan vírgenes con sus atributos, ángeles músicos y arcángeles con alas entrecruzadas. La portada está flanqueada por pilastras rematadas con pináculos. En 1536 se construyó el alero de madera sustentado por canes sobre la portada de la iglesia. La portada está realizada en piedra blanda, toba calcárea y dismicrita (IGLESIA, 2008).

\section{Adquisición de datos e instrumentación}

En proyectos de escaneado láser, las posiciones del escáner deben planificarse cuidadosamente con el fin de garantizar la plena cobertura del monumento arquitectónico dentro de las resoluciones y nivel de precisión requerido. La adquisición de los datos se llevó a cabo con el láser escáner FARO LS 880HE. Se realizaron un total de cuatro estaciones para completar el registro de la portada de la iglesia. El volumen de datos láser fue de aproximadamente 14 millones de puntos (XYZ) junto con sus valores de intensidad. Para texturizar el modelo 3D se utilizaron 16 fotografías (3072×2048 píxeles) capturadas con la cámara Canon EOS D60 y objetivo Sigma 15-30 mm en posición gran angular. La cámara se calibró in situ. Las imágenes se tomaron por la mañana y desde diferentes niveles con la ayuda de una grúa.

\section{Procesamiento de los datos láser}

El primer paso consistió en referir a un único sistema de referencia objeto XYZ el conjunto de datos láser capturados en sistemas de referencia instrumentales (locales). Para ello se situaron esferas (puntos control) con las que fue posible realizar un ajuste en bloque de todos los barridos realizados. El siguiente paso consistió en la limpieza de los datos. Para ello, en primer lugar se filtraron y eliminaron aquellos elementos que no pertenecian a la fachada $y_{1}$ en segundo lugar, se redujo el ruido del escáner. A partir de la nube de puntos registrada, se obtuvo el modelo tridimensional de la portada gótica. En el proceso de edición posterior, los huecos del modelo se cerraron manualmente. Posteriormente, se obtuvo la planta, el alzado y varias secciones a diferentes cotas a partir del modelo denso. También se generaron proyecciones ortogonales sombreadas a escala, de alta resolución (figura 2 ).

\section{Texturizado del modelo}

A partir del modelo 3D y del conjunto de imágenes se obtuvo un modelo fotorrealístico 3D realizando un ajuste en bloque de todos los observables terreno e imagen (la metodología se encuentra detallada en BIOSCA; NAVARRO; LERMA, 2007; LERMA; NAVARRO; CABRELLES et ál., 2010: 499-507). La figura 3 mues- tra dos visualizaciones 3D del producto derivado. Una animación del modelo fotorrealístico 3D se encuentra disponible en http:// gifle.webs.upv.es/descargas/Requena.mpg

\section{CONCLUSIONES}

Este artículo repasa sucintamente los productos que se derivan de la aplicación de la fotogrametria terrestre en labores de documentación patrimonial. Las nuevas tecnologías basadas en el escáner láser, por un lado, y el procesamiento de múltiples imágenes, por otro, abren la puerta a estudios y análisis métricos más objetivos que, acompañados de informes tradicionales, mejoran los registros patrimoniales existentes en la actualidad. Asimismo, pueden utilizarse eventualmente en el caso de actos naturales o humanos fortuitos que los destruyan o los deterioren sustancialmente.

\section{Bibliografía}

BIOSCA, J. M.; NAVARRO, S.; LERMA, J. L. Modelado tridimensional de una bóveda barroca mediante la combinación de láser escáner y fotogrametria [en linea]. En 7a Setmana Geomática Barcelona, 2007 <http://jllerma.webs.upv.es/ pap021.pdf> [consulta: 11/11/2010]

BÖHLER, W. Comparison of 3D laser scanning and other 3D measurement techniques. En BALTSAVIAS, E.; GRUEN, A.; VAN G0OL, L. et ál. (ed.) Recording, Modeling and Visualization of Cultural Heritage. Londres: Taylor \& Francis Group, 2006, pp. 89-99

CABRELLES, M.; SEGUÍ, A. E.; NAVARRO, S. et ál. (2010) 3D Photorealistic Modelling of Stone Monuments by Dense Image Matching. The International Archives of the Photogrammetry, Remote Sensing and Spatial Information Sciences, v. 38, 5, 2010, pp. 121-124

IGLESIA de Santa Maria, Requena [en línea]. s.l.: Conselleria de Cultura, Educació i Esport - Direcció General de Patrimoni Cultural Valencià y Paisajes Españoles, $2008<h t t p: / / w w w . c u l t . g v a . e s / d g p a / d o c u m e n t a c i o n / i n t e r n o / 170$. $\mathrm{pdf}>[03 / 11 / 2008]$

LERMA, J. L. (2010) Heritage Recording Using Image-Based Techniques. En IOANNIDES, M.; ALONZO, A.; GEORGOPOULOS, A. et ál. (ed.) Heritage in the Digital Era. Essex: Multi-Science Publishing, 2010, pp. 83-93

LERMA, J. L.; NAVARRO, S.; CABRELLES, M. et ál. (2010) Terrestrial laser scanning and close range photogrammetry for 3D archaeological documentation: the upper palaeolithic cave of Parpalló as a case study. Journal of Archaeological Science, v. 37, n. ${ }^{\circ} 3,2010$, pp. 499-507

LERMA, J. L.; PÉREZ, C. (2006) 3D photorealistic and interactive reconstruction of covered up frescoes. En BALTSAVIAS, E.; GRUEN, A.; VAN G00L, L. et ál. (ed.) Recording, Modeling and Visualization of Cultural Heritage. Londres: Taylor \& Francis Group, 2006, pp. 485-491

NAVARRO, S.; SEGUÍ, A. E.; PORTALÉS, C. et ál. (2009) Integration of TLS data and non-metric imagery to improve photo models and recording. A case study on Djin Block No. 9, Petra (Jordan). En Proceedings of the 15th International Conference on Virtual Systems and Multimedia. Viena: IEEE Computer Society, 2009, pp. 58-63

SCHOUTEDEN, J.; POLLEFEYS, M.; VERGAUWEN, M.; et ál. (2001) Imagebased 3D acquisition tool for architectural conservation. The International Archive of Photogrammetry, Remote Sensing and Spatial Information Sciences, v. 34, Part 5/C7, 2001, pp. 301-305

TAKASE, Y. (2006) Visualization of cultural heritage with CG and VR. En BALTSAVIAS, E.; GRUEN, A.; VAN GOOL, L.; PATERAKI, M. (ed.) Recording, Modeling and Visualization of Cultural Heritage. Londres: Taylor \& Francis Group, 2006, pp. 407-416 